\section{Minimally Invasive Approach in Treating Large Ovarian Endometrioma}

\section{Bishista Bagchi', Sugata Bhattacharya ${ }^{2}$, Gon Chowdhury Rajib $^{1}$ and Siddhartha Chatterjee ${ }^{1,3 *}$}

${ }^{1}$ Department of Reproductive Medicine, Calcutta Fertility Mission, Kolkata, India

${ }^{2}$ Department of Radiology, Manisha X-Ray Clinic, Kolkata, India

${ }^{3}$ Department of Biochemistry and Endocrinology, Institute of Post Graduate Medical Education \& Research, Kolkata, India

\begin{abstract}
Objective: Management of large ovarian endometriomas has been a potential challenge; be it laparoscopy, open approach or drainage of the cystic fluid. The present procedure has been carried out to benefit young yet to conceive patients to restore ovarian function and facilitate conception.
\end{abstract}

Case series: 3 patients; one presented with history of increasing abdominal girth, pain and infertility; the other with history of loose motion and acute abdominal pain; the third patient had complaints of abdominal pain and infertility. Radiological investigations revealed large cysts in the right and left ovary in the first and third patients respectively; bilateral complex cystic lesions in the second patient. The tumour markers were moderately high (endometriosis); imaging showed benign appearance. Ultrasound-guided drainage of the chocolate-coloured cystic fluid was done using a pigtail catheter. Postoperative period was uneventful.

Conclusion: Minimally invasive treatment of endometrioma which benefits infertile or unmarried patients by preserving the ovaries and fertility henceforth.

Keywords: Infertility; Ovarian endometrioma; Ultrasound guided drain

*Corresponding author: Siddhartha Chatterjee MBBS, DGO, DNB, FRCOG, FICOG, Department of Biochemistry and Endocrinology, Institute of Post Graduate Medical Education \& Research, Kolkata, India, Tel: +91 9830387875; E-mail: sidchat54@gmail.com

Citation: Bagchi B, Bhattacharya S, Rajib GC, Chatterjee S (2019) Minimally Invasive Approach in Treating Large Ovarian Endometrioma. J Reprod Med Gynecol Obstet 4: 024.

Received: July 09, 2019; Accepted: July 12, 2019; Published: July 19, 2019

Copyright: (c) 2019 Bagchi B, et al. This is an open-access article distributed under the terms of the Creative Commons Attribution License, which permits unrestricted use, distribution, and reproduction in any medium, provided the original author and source are credited.

\section{Introduction}

Endometriosis is an enigmatic disease, diagnosed by a combined approach - clinical findings, pelvic ultrasonography and laparoscopy, being the gold standard. It usually presents with moderate to severe pain, infertility, or both, in $35-50 \%$ patients. Although no specific mechanism has been documented but distorted pelvic anatomy, ovulatory abnormalities, impaired hormonal and cell-mediated functions in the endometrium, are considered as the reasons of infertility [1]. Though the confirmation of diagnosis is by laparoscopy but it has been well accepted that the main suspicion of its presence comes from its symptoms and clinical findings along with non-invasive procedures like ultrasonography. The main problem of endometriosis in clinical practice is presence or recurrence of endometrioma which either presents with pain or with associated infertility and a large mass. Recurrence poses a huge problem so far further treatment is concerned.

\section{Case Reports}

\section{Patient 1}

A 27-year-old woman presented at Calcutta Fertility Mission, Kolkata, with complaints of abdominal distension and infertility. There was no history of gastrointestinal or urinary symptoms, no family history of malignancies. On abdominal examination a large ill-defined pelvic-abdominal cystic non-tender mass extending from pubis to the epigastric region was detected, with a dull note on percussion. Intestinal peristaltic sounds were normal. On Transabdominal Ultrasonography (TAS) with Doppler, a large pelvic cystic lesion of (147*87) mm with internal echogenic material with no septation, as seen. The uterus was normal in size with the left ovary in the POD adherent to the uterus. CA-125 was $164.3 \mathrm{IU} / \mathrm{ml}$. Risk of Ovarian Malignancy Algorithm (ROMA) was within normal limit. Abdomino-pelvic Computerized Tomography (CT) findings were consistent with a large well-defined homogeneously cystic lesion originating from the right ovary measuring $(156 \times 96 \times 139) \mathrm{mm}$ in the antero-posterior, transverse, and craniocaudal dimensions, respectively (Figure 1). Our patient was counselled and signed informed consent was obtained for laparotomy if needed and possible oophorectomy. Chocolate coloured fluid was drained using a pigtail catheter (procedure described in detail below) and patient was put on Dienogest ( $2 \mathrm{mg}$ ) for 24 weeks.

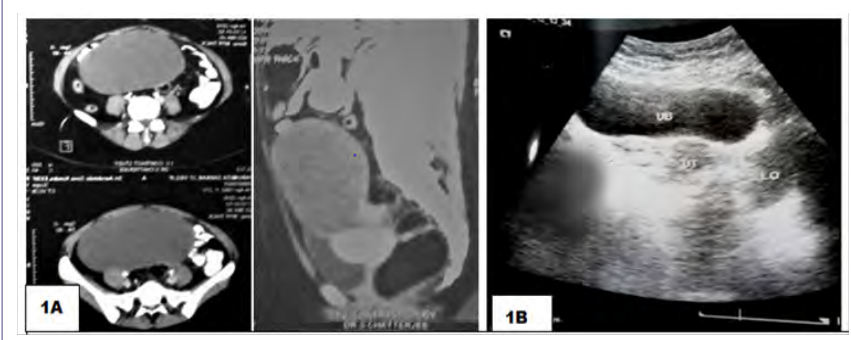

Figure 1A: Abdomino-pelvic Computerized Tomography (CT) findings were consistent with a large well-defined homogeneously cystic lesion originating from the right ovary measuring $(156 \times 96 \times 139) \mathrm{mm}$; 1B) Collapsed cyst wall with normal right ovary post procedure. 
Citation: Bagchi B, Bhattacharya S, Rajib GC, Chatterjee S (2019) Minimally Invasive Approach in Treating Large Ovarian Endometrioma. J Reprod Med Gynecol Obstet 4: 024.

- Page 2 of $4 \cdot$

\section{Patient 2}

A 32year old woman, known case of endometriosis and anxious to conceive, presented with history of acute pain abdomen, recurrent episodes of loose stools and severe dehydration. She was diagnosed to have Subacute Intestinal obstruction and was treated with intravenous antibiotics and was advised laparotomy, elsewhere. Her CECT Whole Abdomen reports revealed complex cystic lesion in right ovary, measuring about $(153 * 59 * 48) \mathrm{mm}$ with multiple thick septations and minimally enhancing solid component and $(71 * 56 * 46) \mathrm{mm}$ complex cyst arising from the left adnexa (Figure 2). CA-125 level was $78 \mathrm{U} / \mathrm{ml}$ and ROMA was within normal limit. Similar procedure was followed in this case and chocolate coloured fluid was drained from both the cysts. The patient was asymptomatic postoperatively and was prescribed Dienogest $(2 \mathrm{mg}$ ) and Ethinyl estradiol (30mcg). She is being monitored presently by serial ultrasound, the last ultrasound (April 2019) revealing 2 cysts $25 \mathrm{~mm}$ each in the right ovary and a $30 \mathrm{~mm}$ cyst in the left ovary.

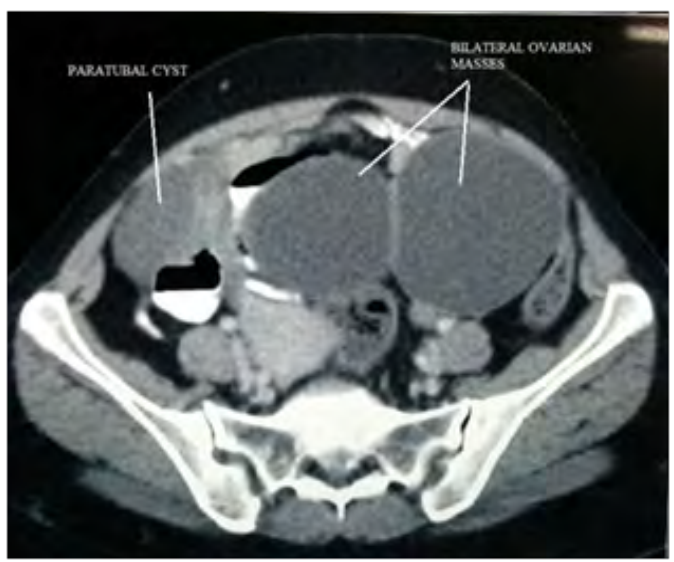

Figure 2: CECT whole abdomen showing bilateral cystic lesions $(153 * 59 * 48) \mathrm{mm}$ with multiple thick septations and minimally enhancing solid component, arising from right adnexa and $(71 * 56 * 46) \mathrm{mm}$ complex cyst arising from the left adnexa; Collapsed cyst wall with normal ovaries was seen on ultrasound post procedure.

\section{Patient 3}

27 year old woman presented with complaints of pain abdomen and infertility. On routine Transvaginal Ultrasound (TVS) and Doppler examination she was diagnosed to have a huge cystic lesion with echogenic material, measuring $(120 * 100) \mathrm{mm}$ with no significant vascularity, arising from the left ovary and the right ovary appeared variegated (Figure 3). She had been advised laparotomy elsewhere and she had come to us as she did not want to get operated as she was concerned about conception. A single dose of LHRH analogue was given and the endometrioma was drained following the same procedure as done in the other cases. Patient was prescribed Dienogest $(2 \mathrm{mg}$ ) for 12 weeks followed by ovulation induction with letrozole (2.5mg) from Day 2-Day 6 and dyhydrogesterone (10mg) from Day19-Day 25 for the next 3 cycles. Patient had conceived on these medications but had a miscarriage after 5 weeks. The ultrasound done recently showed variegated left ovary with no cystic lesion and a $50 \mathrm{~mm}$ cyst arising from the right ovary.

\section{Procedure}

Under aseptic precautions local analgesic infiltration is given and if patient is apprehensive TIVA (Total Intravenous Anaesthesia) is required. TIVA was required in our first patient but the other two procedures were done under local analgesia. Ultrasound performed through abdominal route and the site of puncture $(0.5 \mathrm{~cm})$ over the skin identified, then the Metal Stiffening Cannula covered by the pigtail catheter is introduced into the cyst, guide withdrawn and the catheter remains inside the cyst; chocolate coloured material withdrawn with low pressure pump and 50cc syringe (Figure 4). The entire cyst contents are withdrawn under ultrasound guidance (Figure 5). Patient is reversed if TIVA is used, shifted to ward and kept overnight to observe any complication. Repeat TAS is usually done next morning and the cysts have been found to be collapsed completely with no internal haemorrhage. 3 doses of intravenous antibiotic prophylaxis are given and patient gets discharged the next day.
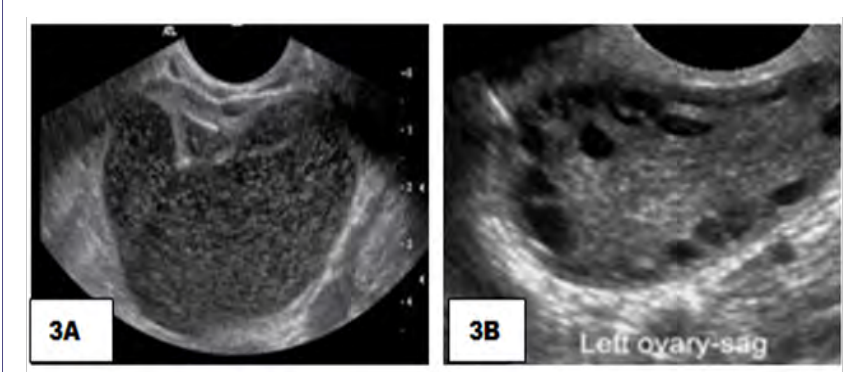

Figure 3A: Transabdominal ultrasound showing a large pelvic cystic SOL of $(120 * 100) \mathrm{mm} ; \mathbf{3 B})$ normal left ovary post procedure.

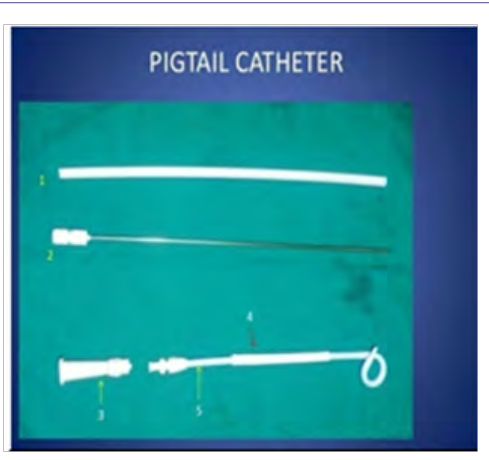

Figure 4: 1) Flexible Stiffening Cannula 2) Metal Stiffening Cannula 3) Connector 4) Drainage catheter 5) Straightener.

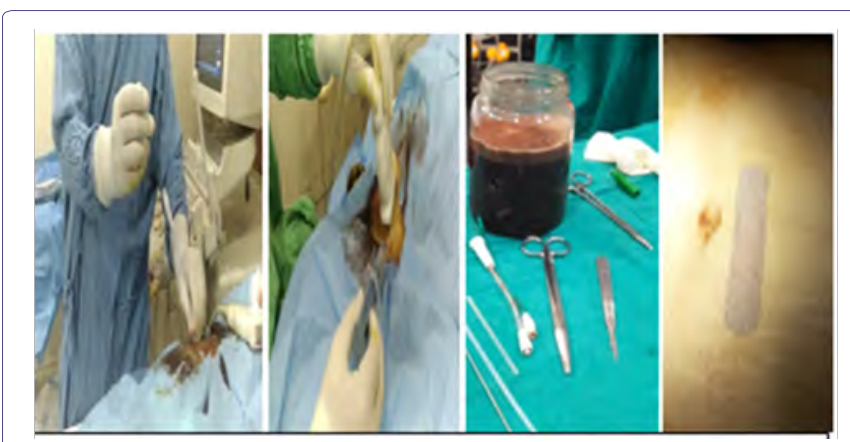

Figure 5: Insertion of pigtail catheter and aspiration of chocolate coloured fluid from the endometrioma. 
Citation: Bagchi B, Bhattacharya S, Rajib GC, Chatterjee S (2019) Minimally Invasive Approach in Treating Large Ovarian Endometrioma. J Reprod Med Gynecol Obstet 4: 024.

\section{Discussion}

The treatment of ovarian endometrioma has been a potential challenge in the field of gynaecology since ages and various mode of management i.e., medical or surgical, have been attempted for the best outcome. In the surgical treatment of benign ovarian cysts in young women, irrespective of its size, one of the main goals is to preserve the reproductive and hormonal functions of the ovaries and prevent recurrence. Laparotomy and ovarian cystectomy is considered as the conventional treatment in cases of large ovarian endometriomas by many surgeons. Inadvertently oophorectomy is one of the unfortunate consequences in such cases. When compared to traditional surgery by laparotomy, operative laparoscopy is associated with shorter hospital stay, faster patient recovery, less incidence of de novo adhesion formation [2]. Laparoscopic approach for the cysts with a diameter greater than $10 \mathrm{~cm}$ presents various difficulties; primarily the rupture of the cysts with spillage of its contents during the introduction of a trocar or Veress needle [3]. Few authors prefer an open technique as the cyst is not aspirated prior to the surgery whereas few prefer cyst size reduction prior to laparoscopy and if ablation is done, it may be incomplete, with a greater risk of recurrence [4,5]. Significant concern has been shown about spillage of tumour cells and its possible worsening of prognosis [6]. Ovarian cyst aspiration by transvaginal route has many advantages like short hospital stay, rapid recovery, excellent patient tolerance, but recurrence rate and chances of infection are higher [7]. Aspiration of simple ovarian cysts by abdominal route during pregnancy is safe, may save surgical intervention and in some cases this can be considered as the definitive treatment [8]. According to few the overall recurrence rate following Fine Needle Aspiration (FNA) was $65 \%$ even after complete aspiration of the content of the cyst. Hence FNA might be proposed in young women with a unilocular ovarian cyst to avoid an immediate surgery and is an important step for diagnosis, in postmenopausal women [9]. It has been shown that $32-63 \%$ of women achieved pregnancy following laparoscopy and drainage of abscess versus $4-15 \%$ in women treated with only antibiotics [10]. Catheter-based sclerotherapy with $95 \%$ ethanol or in situ methotrexate injection is simple, safe, non-invasive and effective in the treatment of selected cases of ovarian endometriomas and ovarian function is also well-preserved in these patients. It has been seen that during a follow-up of about 12.7 months, there was no recurrences of endometrioma and pain was also relieved in all patients $[11,12]$.

The advantage of the present procedure is that it is minimally invasive and complete drainage of the chocolate coloured cystic fluid is possible without any spillage or internal haemorrhage. The drainage is done from the non-dependent part of the cyst which reduces the chances of leakage of the content subsequently in comparison to transvaginal aspiration which is usually done through the most dependent part. Asepsis was strictly maintained by painting and draping of the skin and no saline was introduced to prevent any possibility of infection. Sclerotherapy has not yet been standardized, hence we avoided use of any other agent for fear of infection and we had prescribed Dienogest $(2 \mathrm{mg})$ to them for some time. Percutaneous needle puncture of cyst is established as an effective procedure for ovarian cyst aspiration but it is difficult to aspirate contents of the cyst completely especially in these cases as endometriotic blood is quite thick to drain, which could be drained easily by the wide-bore pigtail catheter. Use of LHRH analogue helps to delay re-collection of the cyst content and hence recurrence. After the procedure patient can be given ovulation induction with letrozole as it will not re-stimulate endometriosis.
Moreover it appears that large-sized endometriomas distort the Tubo-Ovarian Relationship (TOR) and might also have some pressure effect on the ovaries hampering the natural process of ovulation. This can be sited as one of the reasons that one of our patients had conceived with ovulation induction after drainage of endometrioma. The drawbacks of this procedure are small rent in the ovary which usually heals by fibrosis and there might be little bit of spillage of the content of the cyst if the placement of the catheter is improper and recurrence of the cyst as the cyst wall is not excised. But these complications are true even in transvaginal drainage of endometrioma and in laparoscopy. The main advantages of this procedure are preservation of the ovaries of infertile women as well as unmarried young patients seem to outweigh the disadvantages. In addition, the procedure being done under transabdominal ultrasound appears to be convenient for young unmarried patients.

\section{References}

1. Bulletti C, Coccia ME, Battistoni S, Borini A (2010) Endometriosis and infertility. J Assist Reprod Genet 27: 441-447.

2. Yuen PM, Yu KM, Yip SK, Lau WC, Rogers MS, et al. (1997) A randomized prospective study of laparoscopy and laparotomy in the management of benign ovarian masses. Am J Obstet Gynecol 177: 109-114.

3. Tagliabue F, Acquaro P, Confalonieri G, Spagnolo S, Romelli A, et al. (2009) Laparoscopic approach for very large benign ovarian cyst in young woman. J Minim Access Surg 5: 75-77.

4. Nagele F, Magos AL (1996) Combined ultrasonographically guided drainage and laparoscopic excision of a large ovarian cyst. Am J Obstet Gynecol 175: $1377-1378$.

5. Roman H, Quibel S, Auber M, Muszynski H, Huet E, et al. (2015) Recurrences and fertility after endometrioma ablation in women with and without colorectal endometriosis: A prospective cohort study. Hum Reprod 30: 558-568.

6. Sainz de la Cuesta R, Goff BA, Fuller AF Jr, Nikrui N, Eichhorn JH, et al. (1994) Prognostic importance of intraoperative rupture of malignant ovarian epithelial neoplasms. Obstet Gynecol 84: 1-7.

7. Duke D, Colville J, Keeling A, Broe D, Fotheringham T, et al. (2006) Transvaginal aspiration of ovarian cysts: Long-term follow-up. Cardiovasc Intervent Radiol 29: 401-405.

8. Caspi B, Ben-Arie A, Appelman Z, Or Y, Hagay Z (2000) Aspiration of simple pelvic cysts during pregnancy. Gynecol Obstet Invest 49: 102-105.

9. Dordoni D, Zaglio S, Zucca S, Favalli G (1993) The role of sonographically guided aspiration in the clinical management of ovarian cysts. J Ultrasound Med 12: 27-31.

10. Rosen M, Breitkopf D, Waud K (2009) Tubo-ovarian abscess management options for women who desire fertility. Obstet Gynecol Surv 64: 681- 689.

11. Han K, Seo SK, Kim MD, Kim GM, Kwon JH, et al. (2018) Catheter-directed Sclerotherapy for Ovarian Endometrioma: Short-term Outcomes. Radiology 289: 854-859.

12. Shawki HE, Elmorsi M, Samir A, Eissa MK (2011) In situ methotrexate injection after transvaginal ultrasound-guided aspiration of ovarian endometriomas: A randomized controlled trial. Middle East Fertility Society Journal 16: 224-231. 
Citation: Bagchi B, Bhattacharya S, Rajib GC, Chatterjee S (2019) Minimally Invasive Approach in Treating Large Ovarian Endometrioma. J Reprod Med Gynecol Obstet 4: 024.

- Page 4 of 4 • 


\section{Hit \\ HERALD}

Journal of Anesthesia \& Clinical Care

Journal of Addiction \& Addictive Disorders

Advances in Microbiology Research

Advances in Industrial Biotechnology

Journal of Agronomy \& Agricultural Science

Journal of AIDS Clinical Research \& STDs

Journal of Alcoholism, Drug Abuse \& Substance Dependence

Journal of Allergy Disorders \& Therapy

Journal of Alternative, Complementary \& Integrative Medicine

Journal of Alzheimer's \& Neurodegenerative Diseases

Journal of Angiology \& Vascular Surgery

Journal of Animal Research \& Veterinary Science

Archives of Zoological Studies

Archives of Urology

Journal of Atmospheric \& Earth-Sciences

Journal of Aquaculture \& Fisheries

Journal of Biotech Research \& Biochemistry

Journal of Brain \& Neuroscience Research

Journal of Cancer Biology \& Treatment

Journal of Cardiology \& Neurocardiovascular Diseases

Journal of Cell Biology \& Cell Metabolism

Journal of Clinical Dermatology \& Therapy

Journal of Clinical Immunology \& Immunotherapy

Journal of Clinical Studies \& Medical Case Reports

Journal of Community Medicine \& Public Health Care

Current Trends: Medical \& Biological Engineering

Journal of Cytology \& Tissue Biology

Journal of Dentistry: Oral Health \& Cosmesis

Journal of Diabetes \& Metabolic Disorders

Journal of Dairy Research \& Technology

Journal of Emergency Medicine Trauma \& Surgical Care

Journal of Environmental Science: Current Research

Journal of Food Science \& Nutrition

Journal of Forensic, Legal \& Investigative Sciences

Journal of Gastroenterology \& Hepatology Research
Journal of Gerontology \& Geriatric Medicine

Journal of Genetics \& Genomic Sciences

Journal of Hematology, Blood Transfusion \& Disorders

Journal of Human Endocrinology

Journal of Hospice \& Palliative Medical Care

Journal of Internal Medicine \& Primary Healthcare

Journal of Infectious \& Non Infectious Diseases

Journal of Light \& Laser: Current Trends

Journal of Modern Chemical Sciences

Journal of Medicine: Study \& Research

Journal of Nanotechnology: Nanomedicine \& Nanobiotechnology Journal of Neonatology \& Clinical Pediatrics

Journal of Nephrology \& Renal Therapy

Journal of Non Invasive Vascular Investigation

Journal of Nuclear Medicine, Radiology \& Radiation Therapy

Journal of Obesity \& Weight Loss

Journal of Orthopedic Research \& Physiotherapy

Journal of Otolaryngology, Head \& Neck Surgery

Journal of Protein Research \& Bioinformatics

Journal of Pathology Clinical \& Medical Research

Journal of Pharmacology, Pharmaceutics \& Pharmacovigilance

Journal of Physical Medicine, Rehabilitation \& Disabilities

Journal of Plant Science: Current Research

Journal of Psychiatry, Depression \& Anxiety

Journal of Pulmonary Medicine \& Respiratory Research

Journal of Practical \& Professional Nursing

Journal of Reproductive Medicine, Gynaecology \& Obstetrics

Journal of Stem Cells Research, Development \& Therapy

Journal of Surgery: Current Trends \& Innovations

Journal of Toxicology: Current Research

Journal of Translational Science and Research

Trends in Anatomy \& Physiology

Journal of Vaccines Research \& Vaccination

Journal of Virology \& Antivirals

Submit Your Manuscript: http://www.heraldopenaccess.us/Online-Submission.php 